\title{
Structure and Reactivity of the $N$-Acetyl-Cysteine Radical Cation and Anion: Does Radical Migration Occur?
}

\author{
Sandra Osburn, ${ }^{1}$ Giel Berden, ${ }^{2}$ Jos Oomens, ${ }^{2,3}$ Richard A. J. O'Hair, ${ }^{4,5,6}$ Victor Ryzhov ${ }^{1}$ \\ ${ }^{1}$ Department of Chemistry and Biochemistry, and Center for Biochemical and Biophysical Studies, Northern Illinois \\ University, DeKalb, IL 60115, USA \\ ${ }^{2}$ FOM Institute for Plasma Physics, Nieuwegein, The Netherlands \\ ${ }^{3}$ University of Amsterdam, Amsterdam, The Netherlands \\ ${ }^{4}$ School of Chemistry, The University of Melbourne, Melbourne, Australia \\ ${ }^{5}$ Bio21 Institute of Molecular Science and Biotechnology, The University of Melbourne, Melbourne, Australia \\ ${ }^{6} \mathrm{ARC}$ Centre of Excellence for Free Radical Chemistry and Biotechnology, Melbourne, Australia
}

\begin{abstract}
The structure and reactivity of the $\mathrm{N}$-acetyl-cysteine radical cation and anion were studied using ion-molecule reactions, infrared multi-photon dissociation (IRMPD) spectroscopy, and density functional theory (DFT) calculations. The radical cation was generated by first nitrosylating the thiol of $N$-acetyl-cysteine followed by the homolytic cleavage of the S-NO bond in the gas phase. IRMPD spectroscopy coupled with DFT calculations revealed that for the radical cation the radical migrates from its initial position on the sulfur atom to the a-carbon position, which is $2.5 \mathrm{~kJ} \mathrm{~mol}^{-1}$ lower in energy. The radical migration was confirmed by time-resolved ion-molecule reactions. These results are in contrast with our previous study on cysteine methyl ester radical cation (Osburn et al., Chem. Eur. J. 2011, 17, 873-879) and the study by Sinha et al. for cysteine radical cation (Phys. Chem. Chem. Phys. 2010, 12, 9794-9800) where the radical was found to stay on the sulfur atom as formed. A similar approach allowed us to form a hydrogen-deficient radical anion of $N$-acetyl-cysteine, $(\mathrm{M}-2 \mathrm{H})^{\circ}$. IRMPD studies and ion-molecule reactions performed on the radical anion showed that the radical remains on the sulfur, which is the initial and more stable (by $63.6 \mathrm{~kJ} \mathrm{~mol}^{-1}$ ) position, and does not rearrange.
\end{abstract}

Key words: Radical ions, $N$-acetyl-cysteine, Radical rearrangement, lon-molecule reactions, IRMPD spectroscopy, DFT calculations

\section{Introduction}

There are numerous examples where radicals play key

1 roles in the active site of enzymes [1-12]. These radicals are normally located on a reactive amino acid side

Electronic supplementary material The online version of this article (doi:10.1007/s13361-011-0198-5) contains supplementary material, which is available to authorized users.

Correspondence to: Victor Ryzhov; e-mail: ryzhov@niu.edu chain (cysteine [2], methionine, tyrosine, or tryptophan [10]) or on the peptide backbone, namely at the $\alpha$-carbon positon of glycine [13]. In some instances, it has also been shown that the radical migrates to different positions in the inactive form $[4,5,9]$. In those cases, the radical is relocated to the less reactive positions of the sulfur atom on a cysteine residue $[4,5,9]$ or to the glycine $\alpha$-carbon $[6,11]$. In most enzymes, such radical rearrangement is considered to be a protective mechanism. Radicals in proteins can also be very destructive if they form at or migrate to the wrong place [13-19]. Once generated, the radicals can cause oxidative 
cleavage along the backbone of the protein [13-19], which could cause the loss of function of the protein.

While multiple methods have been used to study radical location and reactivity in proteins [13], small model systems very often add detailed insights into relative stability of the radical site, and its reactivity towards specific targets and allow reaction kinetics to be studied [20]. Radicals in amino acids, peptides, and their derivatives have been examined using various experimental $[7,8,21]$ and computational techniques [13-15].

Mass spectrometry (MS) has recently emerged as a powerful tool for the generation of radical ions in the gas phase and their subsequent studies. Not counting the proteomics-targeted techniques of electron capture dissociation and electron transfer dissociation, which both produce hydrogen-rich radical cations $(\mathrm{M}+\mathrm{nH})^{(\mathrm{n}-1)^{+}}$, a wide range of MS-based approaches have been developed to generate hydrogen-deficient radical cations $\mathrm{M}^{\circ+}$. With the advent of electrospray ionization, electron ionization methods, first reported by Andersson in 1958 [22] have largely been supplanted by methods involving collision induced dissociation (CID) or UV photodissociation of peptide derivatives. Examples include CID of: (1) redox active metal complexes composed of a metal in a higher oxidation state (like $\mathrm{Fe}^{3+}$ or $\mathrm{Cu}^{2+}$ ), peptide or amino acid of interest, and an auxiliary ligand [23-31]; (2) an amino acid or peptide covalently modified to include a derivative with a weak bond that is susceptible to homolytic cleavage, such as peroxycarbamate derivatives to introduce a radical on lysine $[24,25]$ or the Nterminus of a peptide ${ }^{26}$ and serine nitrate esters to produce carbon centered radicals [27, 28]. Another method involves the UV photodissociation of iodotyrosine [29, 30] or modified phosphorylated serine and threonine [31]. Unfortunately, none of these MS-based techniques has the ability to generate thiyl radicals on the cysteine side chain. Recently, our group has taken advantage of the labile nature of $S$-nitroso bond to generate radical cations of cysteine [32].

With the continuing progress in the area of generation of radical ions, there has been a greater interest in understanding their structure and reactivity. An emerging method for determining the structure of these radical ions is through infrared multiple photon dissociation (IRMPD) spectroscopy. Since the first study on the structure of histidine radical cation [33], two other studies were performed on the cysteine radical cation [34] and its methyl ester [35]. Theoretical calculations have also been actively employed [36]. The reactivity of radical ions in the gas phase can also provide vital information about the radical position and its possible rearrangement pathways. While radical migration is often accompanied by significant energy barriers, CID conditions (even at low-energy CID in ion traps) provide enough energy to overcome those barriers as has been shown by us [32, 37] and others [38]. Ion-molecule reactions in the gas phase provide much less energetic reaction conditions and can be used as a probe of the radical structure $[27,28,39,40]$.
We have developed a robust approach to probe the structure of cysteine-based radical cations via ion-molecule reactions [35]. Sulfur-based radicals display characteristic reactivity towards typical radical probe reagents such as dimethyl disulfide and allyl iodide. Carbon-based radicals, on the other hand, are unreactive towards those species, although they do react with dioxygen, $\mathrm{NO}$, and $\mathrm{NO}_{2}[28$, 41]. We used theoretical calculations and IRMPD spectroscopy to confirm our ion-molecule reaction results for the cysteine methyl ester radical cation [19]. The focus of this study is on the structure and reactivity of the $\mathrm{N}$-acetylcysteine (N-Ac-Cys) radical cation.

While the formation, gas phase chemistry, and structure of radical cations of amino acids and peptides are actively being explored, their negatively charged counterparts have been largely neglected. Exceptions include $\mathrm{Chu}$ and coworkers' use of ternary metal complexes $[42,43]$ and the use of ion-ion reactions between multiply deprotonated peptides and cations [44]. Being able to generate peptide radical anions is equally important, as many peptides are negatively charged in solution. For instance, the common radical scavenger glutathione ( $\gamma$-Glu-Cys-Gly) carries a negative charge in solution [45]. Furthermore, the relative stability of radical structures is greatly affected by the charge sign [19]. In this work we exploit the utility of $S$ nitroso chemistry to generate for the first time the hydrogen-deficient radical anion of N-Ac-Cys and study its gas-phase reactivity and structure.

\section{Experimental}

\section{Chemicals and Reagents}

All chemicals and reagents were used as received without any further purification. $N$-acetyl-L-cysteine, methanol (HPLC grade), tert-butylnitrite, dimethyl sulfide, allyl bromide, allyl iodide, and dimethyl disulfide were all purchased from Sigma-Aldrich (Milwaukee, WI, USA).

\section{Ion-Molecule Reactions}

Ion-molecule reactions were carried out using a Bruker Esquire 3000 quadrupole ion trap mass spectrometer (Bruker Daltonics, Bremen, Germany) modified to conduct ionmolecule reactions as described previously [46]. Nitrosylated $\mathrm{N}$-Ac-Cys was generated by allowing a 1.5:1 mixture of tert-butylnitrite and a $1 \mathrm{mM}$ solution of $N$-acetyl-cysteine (in 50/50 methanol:water with $1 \%$ acetic acid) to react for $10 \mathrm{~min}$. at room temperature. The reaction mixture was diluted 100-fold using 50/50 methanol:water with $1 \%$ acetic acid and introduced into the ESI source of the mass spectrometer at a flow rate of $5 \mu \mathrm{L} \mathrm{min}{ }^{-1}$. The sheath gas, capillary voltage, and temperature were adjusted to about 10 arbitrary units, $3.0 \mathrm{kV}$, and $250{ }^{\circ} \mathrm{C}$, respectively. Radical cations and anions of N-Ac-Cys were produced either by either CID or in-source fragmentation. When 
using CID, the protonated (or deprotonated) $S$-nitrosylated $\mathrm{N}$-Ac-Cys was mass selected and then subjected to CID using collision energy sufficient to dissociate the majority of the precursor ions. When using in-source fragmentation, the voltages at the source were optimized for the dissociation of the precursor ions without mass selection. The radical ion was then mass selected and allowed to react with the neutral reagent introduced into the trap via a pulsed valve (as previously described [46]) or through a leak valve. The pressure of neutrals was about $1 \times 10^{-7}$ Torr in the ion trap region as estimated by fast ion-molecule reactions. The scan delay was varied from 0 to $7500 \mathrm{~ms}$ allowing the acquisition of mass spectra at different reaction time points.

\section{Infrared Multiple-Photon Dissociation Spectroscopy}

IRMPD spectroscopy studies were carried out at the free electron laser for infrared experiments (FELIX) facility located at the FOM-Institute for Plasma Physics Rijnhuizen in Nieuwegein (The Netherlands) [47]. The nitrosylated acetyl-cysteine was generated as described above with the slight modification that its end concentration was $1 \mathrm{mM}$. Once generated, the nitrosylated precursor was introduced into a custom-built FT-ICR mass spectrometer [48] equipped with an orthogonal Z-spray electrospray ionization source. Operating parameters for ESI were optimized to maximize formation and transfer of ions to the ICR cell. A DC potential switch was applied to the octopole ion guide to trap the ions in the ICR cell without using a gas pulse [49], thus eliminating collisional heating of the ions. The formation of $\mathrm{N}$-Ac-Cys radical ions from the protonated or deprotonated $S$-nitrosylated N-Ac-Cys was induced by raising the cone voltage to cause in-source fragmentation. The radical ion was isolated for IRMPD studies using a stored waveform inverse Fourier transform (SWIFT) pulse. Infrared spectra were collected by monitoring the efficiency of IRMPD as a function of laser wavelength. To produce infrared spectra, the free electron laser was scanned in $0.02-0.04 \mu \mathrm{m}$ increments between 5.5 and $8.5 \mu \mathrm{m}$ and the product ion and precursor ion intensities were measured at each step using the excite/detect sequence of the FT-ICR-MS [50] after irradiation with FELIX [51]. The IRMPD yield is determined by normalizing the fragment intensity to the total ion intensity, and linearly corrected for variations in FELIX power over the spectral range.

\section{Density Functional Theory Calculations}

All geometry optimizations and harmonic vibrational frequencies were calculated using the Gaussian 09 suite of programs [52] and the hybrid B3LYP functional. Initial geometry optimizations were performed using the relatively small 3-21 $\mathrm{G}^{*}$ basis set. All minima located were reoptimized using the same functional and the $6-311++\mathrm{G}(\mathrm{d}$, p) basis set. All transition state calculations were performed using the QST2 function within Gaussian. In most cases, intrinsic reaction coordinate (IRC) calculations were used to confirm that the transition states linked the correct minima that represent pre- and post-transformation structures. Vibrational frequency calculations were performed on the structures optimized at the B3LYP/6-311++G(d,p) level of theory and used to determine whether optimized structures were true minima (no imaginary frequencies) or transition states (one imaginary frequency), to determine zero-point energy corrections to electronic energies (used unscaled), and to predict infrared spectra for comparison to experimental IRMPD spectra. For comparison of DFT spectra to IRMPD spectra, the computed frequencies were scaled by a factor of 0.98 , which is known to be adequate at the current level of theory $[53,54]$. Theoretical IR spectra from the Gaussian output were convoluted with a $20 \mathrm{~cm}^{-1}$ FWHM Lorentzian line shape. Theoretical and experimental spectra were normalized along the y-axis (relative intensity).

\section{Results and Discussion}

\section{Radical Cation of $N$-Acetyl-Cysteine}

Figure 1a shows the formation of the $N$-acetyl-cysteine radical cation generated by the fragmentation of the protonated nitrosylated precursor via the loss of ${ }^{\circ} \mathrm{NO}$ $(30 \mathrm{Da})$. This ${ }^{\circ} \mathrm{NO}$ loss is the lowest energy fragmentation pathway as was established previously [32] and has been exploited by our group in the study of other cysteine derivatives [35] and cysteine-containing peptides [37]. Based on this, we know that the initial radical location is on the sulfur atom.

A major factor in the normal function of enzymes with radicals at their active sites and radical-mediated damage in proteins is the ability for the radical to migrate to

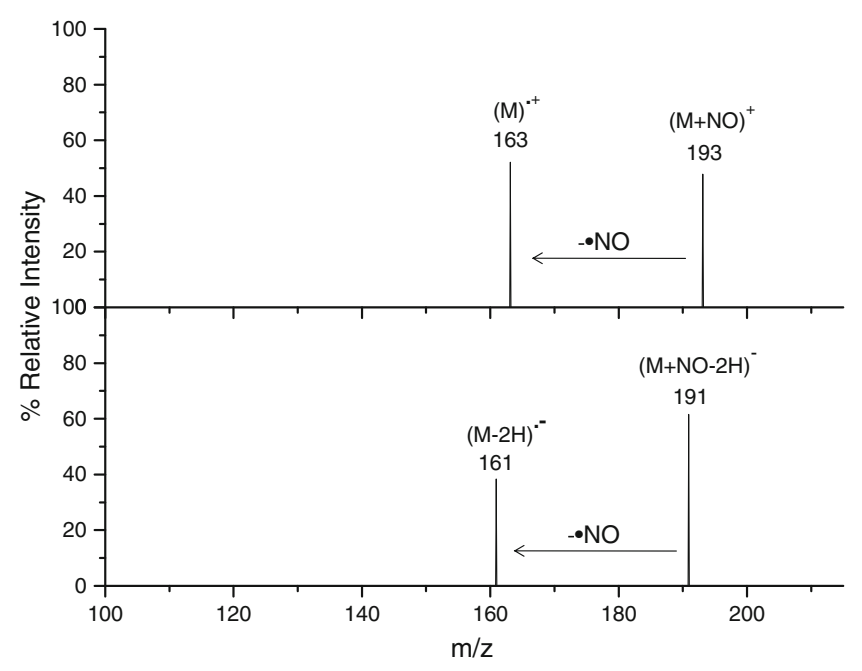

Figure 1. CID of nitrosylated $N$-acetyl-cysteine ion to generate the radical (a) cation and (b) anion of acetyl cysteine 
different locations via hydrogen abstraction making the structure of gas-phase radicals and their ability to migrate a subject of great interest. The most stable location of the radical in peptide systems is commonly believed to be the $\alpha$-carbon position [41]. Previous theoretical studies performed recently by Siu's group showed that the transfer of a radical from one $\alpha$-carbon to the next in triglycine involves a high activation energy $\left(165-261 \mathrm{~kJ} \mathrm{~mol}^{-1}\right)[55$, 56]. It was also calculated by us that the energy barrier for the sulfur-to- $\alpha$-carbon radical migration in the cysteine methyl ester was quite high $\left(171 \mathrm{~kJ} \mathrm{~mol}^{-1}\right)$ [35] hence this migration was not observed experimentally. Scheme 1 shows the various isomers of the acetyl-cysteine radical cation. Based on our calculations, Structure 2, which has the radical located on the $\alpha$-carbon, is $2.5 \mathrm{~kJ} \mathrm{~mol}^{-1}$ lower in energy than Structure 1, which has the radical located on the sulfur.

Figure 2 shows the experimentally generated IR spectrum of $N$-acetyl-cysteine radical cation (Figure 2a) compared with the calculated IR spectra for the two lowest energy structures of the radical cation (sulfur radical, Figure $2 \mathrm{~b}$ and $\alpha$-carbon radical, Figure 2c). The most characteristic band is the carbonyl stretch of the $-\mathrm{COOH}$ moiety. In the S-based radical IR spectrum, it appears at $1780 \mathrm{~cm}^{-1}$ indicative of the free carboxyl moiety, while in the $\alpha$-carbon, the corresponding band is red-shifted to $1710 \mathrm{~cm}^{-1}$ due to high level of resonance in the structure (see Scheme 1). In the comparison, it is clear that neither of the low energy structures can account for all spectral features. However, when the two calculated spectra are summed together (in a 70:30 ratio for the sulfur: $\alpha$-carbon radicals, respectively) and compared with the experimental IR spectrum (Figure 2d) there is a good match between them. This strongly suggests that both isomers of the radical cation are present in the gas phase during the IRMPD experiment, which further suggests that radical rearrangement is occurring on the experimental time frame. To further investigate whether radical rearrangement is occurring, ion-molecule reactions involving the $\mathrm{N}$-Ac-Cys radical cation and several volatile neutrals were performed.
The radical cation generated via CID of the nitrosylated precursor reacted with dimethyl disulfide, allyl bromide, and allyl iodide (Figure 3) and was found to be quite reactive with all of these neutrals, which is characteristic of the radical located at the sulfur atom as we have recently shown [35]. Figure 4 shows a comparison of the reactivity of the radical cation generated via CID (Figure $4 \mathrm{a}$ ) and in-source fragmentation (Figure 4b) with dimethyl sulfide under identical conditions. Both spectra show the same type of radical chemistry (Equation 1):

$$
\mathrm{M}^{\bullet+}+\mathrm{CH}_{3} \mathrm{SCH}_{3} \rightarrow \mathrm{M}-\mathrm{CH}_{3}^{+}+{ }^{\bullet} \mathrm{SCH}_{3}
$$

However, it is obvious that the radical ions generated by CID are much more reactive (close to collision rate) than those produced by in-source fragmentation. The behavior of the CID-generated species is consistent with the radical being located on the sulfur atom. When the radical cation was formed via in-source fragmentation and then isolated in the trap and allowed to react with dimethyl disulfide, there was a major decrease in reactivity. This suggests that the sulfur radical rearranged into an unreactive species. This difference in reactivity can be explained by the fact that when the radical is formed by CID it is immediately formed in the ion trap and does not have time to rearrange before it reacts with the neutral. In contrast, the radical formed by in-source fragmentation has time to undergo thousands of collisions in the ion guides before it enters the ion trap, thus allowing the radical more time and energy from collisions to rearrange before coming into contact with the dimethyl sulfide neutral. An alternative explanation is that the radical may rearrange via ion-molecule catalytic processes involving background ESI solvents present in high concentrations in the skimmer-cone ("in source") region. A possible mechanism that might operate involves proton transport catalysis [57] which occurs via ion-molecule complexes. Such isomerization reactions have been
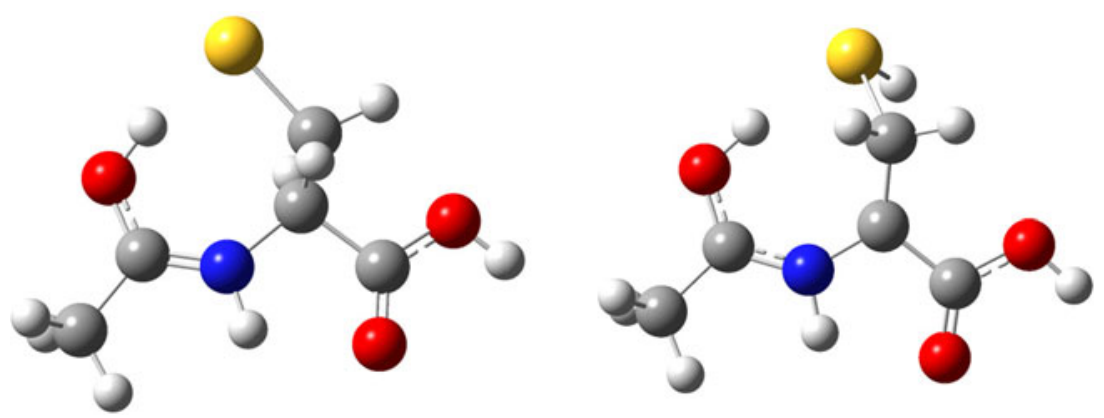

$$
\begin{gathered}
\text { Sulfur Radical } \\
0.0 \mathrm{~kJ} \mathrm{~mol}^{-1}
\end{gathered}
$$

$$
\begin{aligned}
& \alpha \text {-carbon Radical } \\
& -2.5 \mathrm{~kJ} \mathrm{~mol}^{-1}
\end{aligned}
$$

Scheme 1. Low-energy structures of $\mathrm{N}$-acetyl-cysteine radical cation calculated by DFT: (a) sulfur radical, (b) $\alpha$-carbon radical 

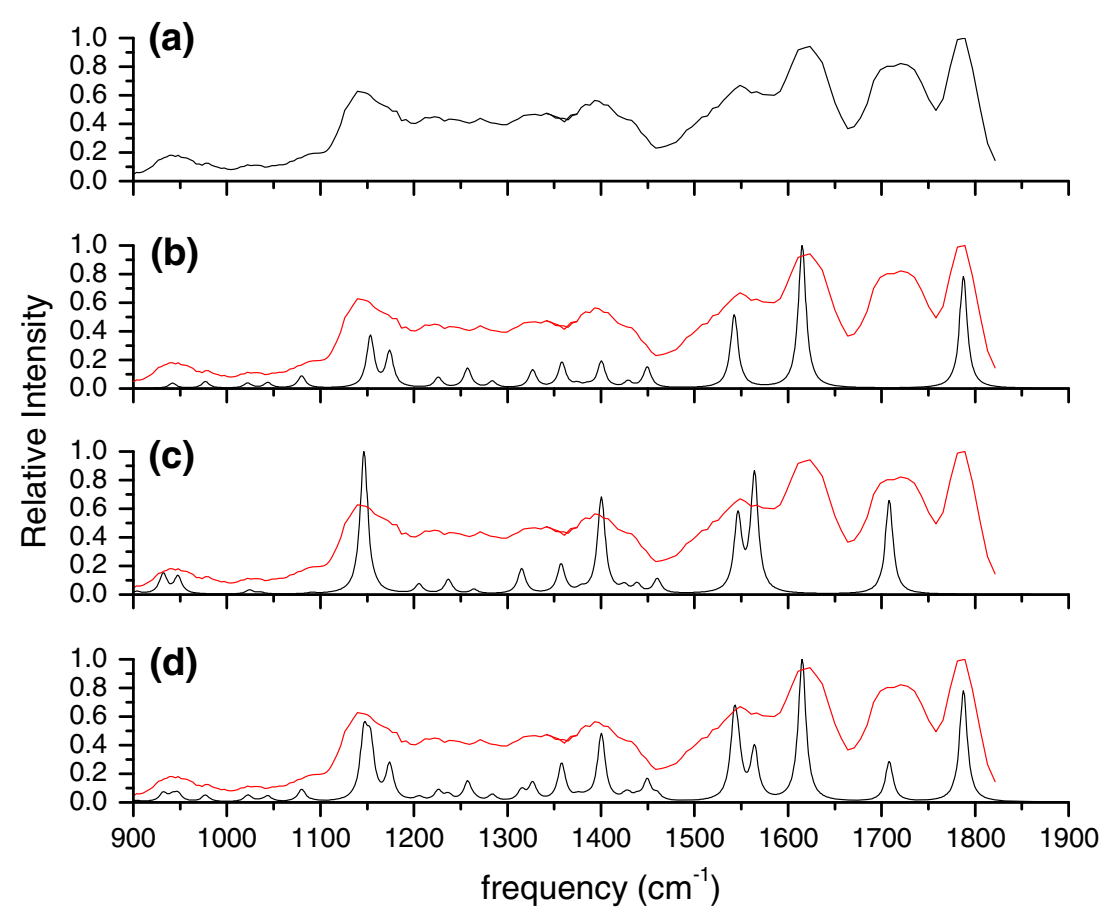

Figure 2. Comparison between experimental and theoretical IR spectra for $N$-acetyl-cysteine radical cation: (a) experimental spectrum, (b) theoretical sulfur radical spectrum, (c) theoretical $\alpha$-carbon radical spectrum, and (d) theoretical sulfur and $\alpha-$ carbon spectra summed together. The experimental spectrum (red trace) is overlaid on the theoretical spectra

observed for a large number of systems including enol/ keto radical cation tautomers [58] and conventional radical cations/distonic ions [59].

To further assess the possibility of partial radical migration, kinetic plots of ion-molecule reactions were recorded (Figure 4c, d). The kinetic plot shows that for the radical generated by CID (Figure 4c) the reaction with dimethyl sulfide goes to completion which would be the case with the sulfur radical, as observed in our previous studies for $\mathrm{CysOMe}^{\cdot+}$ reactivity [35]. For the radical generated by in-source fragmentation the kinetics are not consistent with the simple exponential decay of the starting

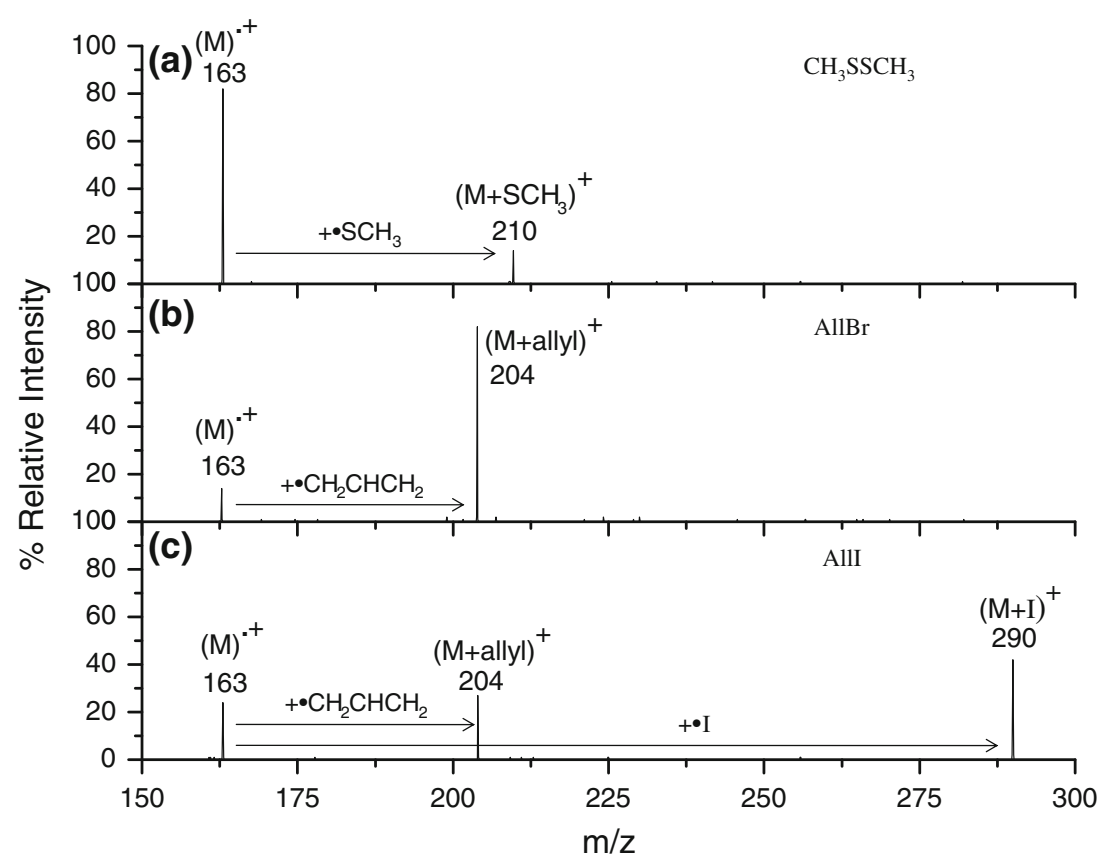

Figure 3. Ion-molecule reactions of the radical cation of $N$-acetyl-cysteine with (a) dimethyl disulfide, (b) allyl bromide, and (c) allyl iodide. Pressure of the neutrals is ca. $10^{-7}$ Torr, reaction time is $400 \mathrm{~ms}$ 


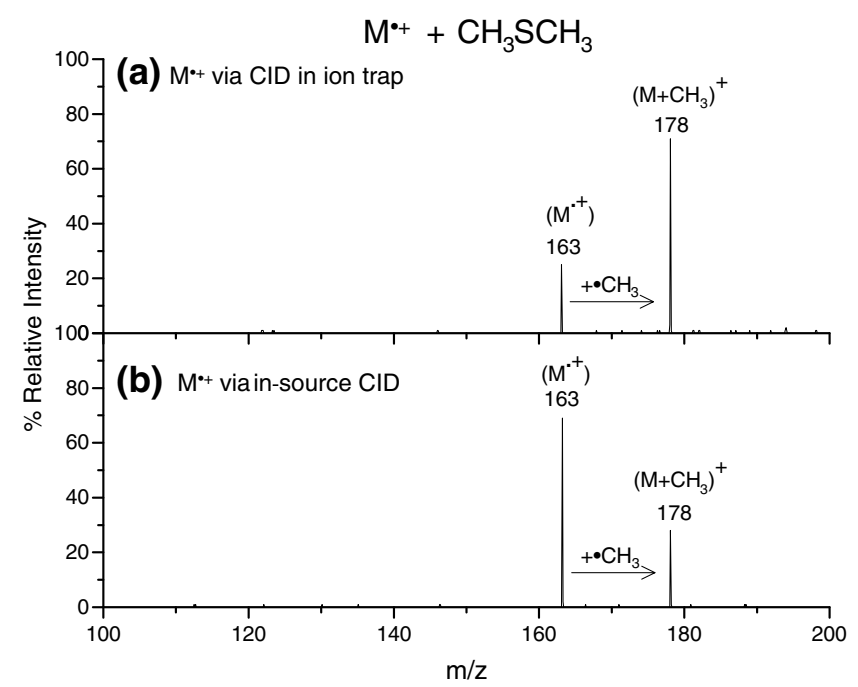

(c)

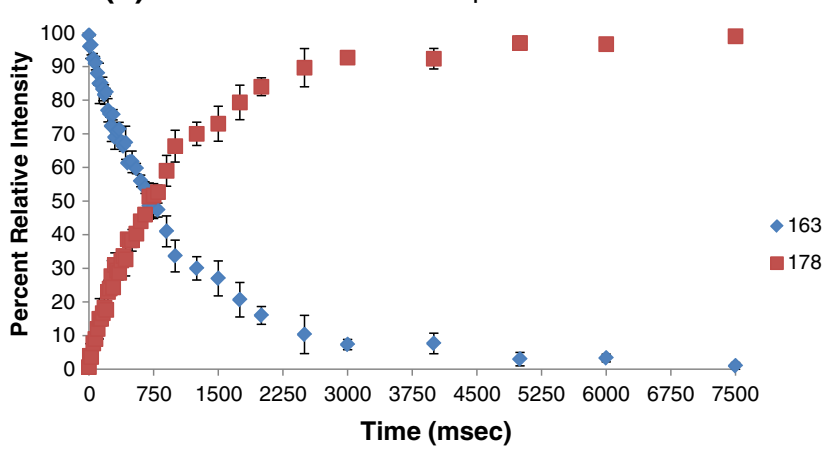

(d)

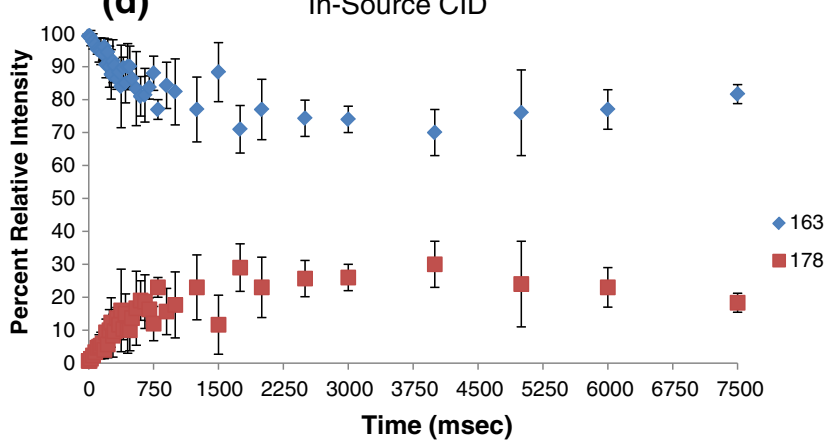

Figure 4. Mass spectrum of the radical cation of $N$-acetylcysteine formed via (a) CID and (b) in-source fragmentation reacting with dimethyl sulfide. Pressure of the neutral is ca. $10^{-7}$ Torr, reaction time is $800 \mathrm{~ms}$. Kinetic plots of the radical cation formed via (c) CID and (d) in-source fragmentation reacting with dimethyl sulfide

radical cation. Instead, the reaction stops after some period, indicating a possible radical migration, since $\alpha$-carbon radicals were shown not to be reactive towards these neutrals [27]. This type of kinetic study was also performed with the volatile neutral dimethyl disulfide with similar results (Figure S4).

Since the calculations done by us here and other groups in the past show that the $\alpha$-carbon is the most stable radical position $[14,35,55,56]$, we determined the lowest energy pathway through which the N-Ac-Cys radical cation would have to go to rearrange. Figure S1 shows the lowest energy pathway calculated for the rearrangement. It is a single step process in which there are no conformational changes between the two structures but simply a transfer of the radical from the sulfur to the $\alpha$-carbon through a hydrogen atom transfer. The energy required for this is $117 \mathrm{~kJ} \mathrm{~mol}^{-1}$, which is significantly less than the same transfer calculated for the cysteine methyl ester radical cation $\left(171 \mathrm{~kJ} \mathrm{~mol}^{-1}\right)$ [35]. This decrease in energy to cross the barrier may be the result of the charge on the carbonyl oxygen of the acetyl group for $N$-acetyl cysteine. In contrast, in the cysteine methyl ester radical cation the sulfur-to- $\alpha$-carbon migration requires not only the hydrogen atom transfer (radical migration) but also the proton (charge) migration from the amino group to the carbonyl oxygen, which leads to an extra step in the mechanism and increases the overall reaction barrier.

Other pathways were also explored to determine if they were potentially lower in energy (Figures S2, S3). In those two pathways, the key steps involve a five-membered (Figure S2) and a three-membered (Figure S3) transition state, but both of them are higher in energy (143 and $226 \mathrm{~kJ} \mathrm{~mol}^{-1}$, respectively). Several other pathways were calculated which involved less sterically strained intermediates, however, in each instance for hydrogen abstraction to occur the linearity of the $\alpha$-carbon N-Ac-Cys cation stabilized by the resonance throughout the ion (see Scheme 1) would have to be disrupted which resulted in an even higher barrier (data not shown).

\section{Radical Anion of N-Acetyl-Cysteine}

We took advantage of the same $S$-nitroso chemistry to prepare the negative counterpart, the hydrogen deficient radical anion of N-Ac-Cys, $(\mathrm{M}-2 \mathrm{H})^{\circ-}$. Figure $1 \mathrm{~b}$ shows the formation of the acetyl-cysteine radical anion generated from the fragmentation of the deprotonated nitrosylated precursor via the loss of ${ }^{\circ} \mathrm{NO}(30 \mathrm{Da})$. This is the first example of forming a radical anion in the gas-phase from an S-nitroso derivative. Obviously, the homolytic cleavage of the weak S-NO bond dominates the CID process independent of the charge on the ion. This class of radical anions, $(\mathrm{M}-2 \mathrm{H})^{\circ}$, should serve as the appropriate model for studying radical processes in proteins since it possesses the deprotonated carboxylate and the initial radical location on the sulfur atom, similar to the thiol protein/peptide radicals in solution.

Once the radical anion was generated, IRMPD spectroscopy and reactivity experiments similar to those described above for the radical cation were performed. Scheme 2 shows two calculated lowest energy isomeric forms of the $\mathrm{N}-$ Ac-Cys radical anion. Structure 1, which has the radical located on the sulfur, is lowest in energy. Structure 2, which has the radical located on the $\alpha$-carbon, is much higher in energy than structure $1\left(63.6 \mathrm{~kJ} \mathrm{~mol}^{-1}\right)$. This is not 


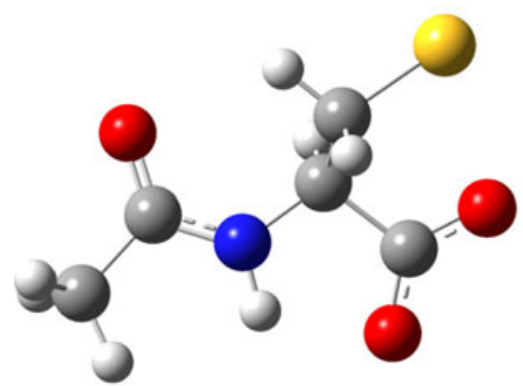

Sulfur Radical

$0.0 \mathrm{~kJ} \mathrm{~mol}^{-1}$

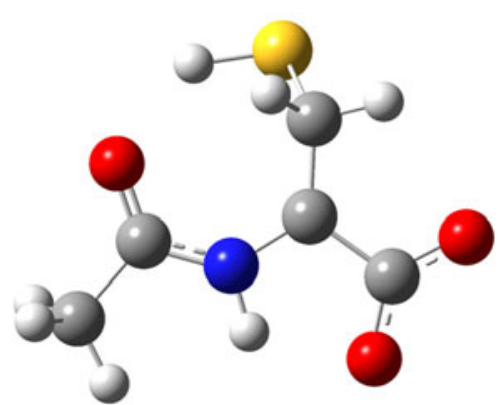

$\alpha$-carbon Radical

$63.6 \mathrm{~kJ} \mathrm{~mol}^{-1}$

Scheme 2. Low-energy structures of $N$-acetyl-cysteine radical anion calculated by DFT: (a) sulfur radical, (b) a-carbon radical

unexpected as in the anion the $\alpha$-carbon radical is not stabilized by the captodative effect [60-62].

Figure 5a shows the experimentally generated IR spectrum for N-Ac-Cys radical anion and its comparison to the calculated spectra for the two lowest energy isomers of the radical anion, the sulfur and the $\alpha$-carbon radicals (Figure 5b, c, respectively). This comparison shows that the sole species present in the gas phase is that with the radical located on the sulfur atom. Theoretical spectra for both structures include the symmetric $\left(1480 \mathrm{~cm}^{-1}\right)$ and asymmetric $\left(1610 \mathrm{~cm}^{-1}\right)$ stretches of the $\mathrm{CO}_{2}^{-}$moiety. The differences between the two theoretical spectra are evident in the analysis of the $\mathrm{C}=\mathrm{O}$ stretch of the acetyl amide group. It is located at $1675 \mathrm{~cm}^{-1}$ in the S-based radical, characteristic of a free amide, while in the $\alpha$ carbon structure it is red-shifted to $1635 \mathrm{~cm}^{-1}$ due to conjugation to the radical. Another prominent feature present in the $\alpha$-carbon calculated spectrum and absent in the experimental spectrum is the strong absorption at $1280 \mathrm{~cm}^{-1}$, which is due to stretching of the $\mathrm{C}-\mathrm{N}$ bond enhanced by resonance effects.

Figure 6 shows the ion-molecule reactions of the radical anion with dimethyl disulfide, allyl bromide, and allyl iodide. The anion was reactive towards all of these neutrals, although the reactions rates were somewhat lower than those for the radical cation. To our knowledge, this is the first reported gas-phase reactivity study of radical anions of an amino acid derivative.

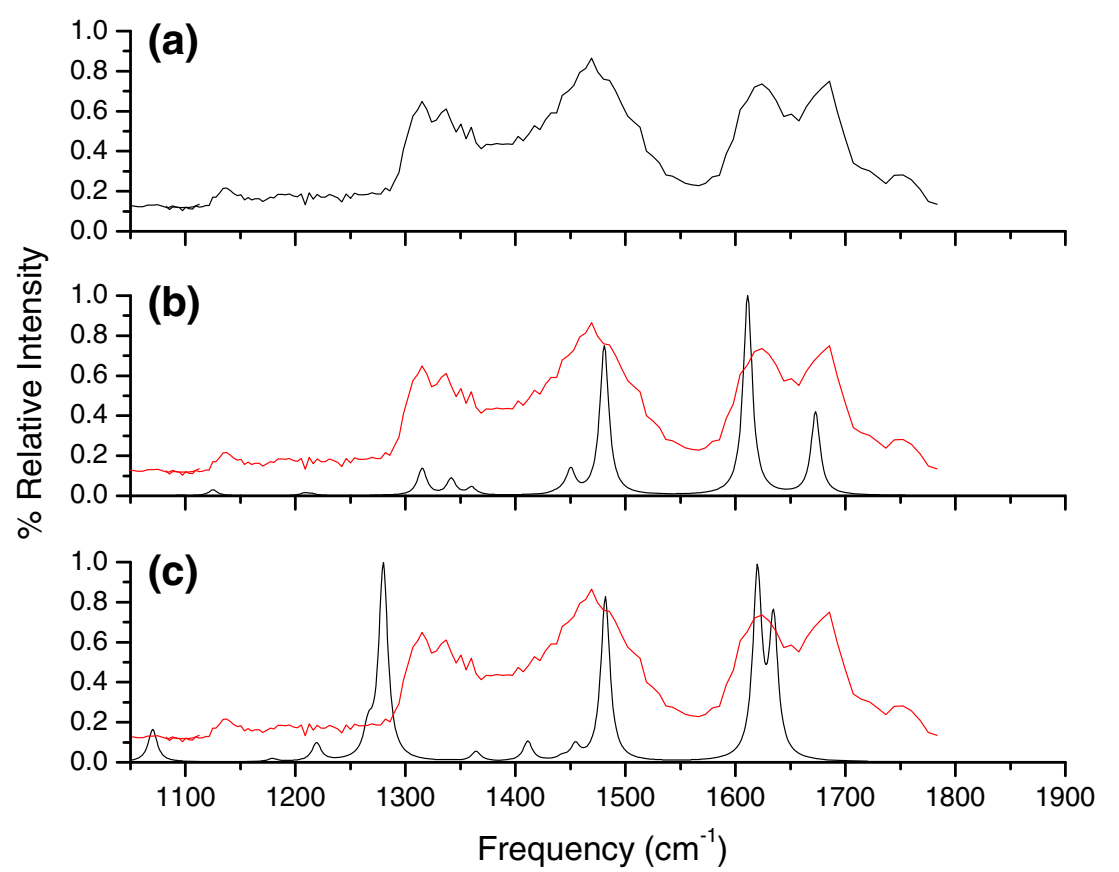

Figure 5. Comparison between experimental and theoretical IR spectra for $N$-acetyl-cysteine radical anion: (a) experimental spectrum, (b) theoretical sulfur radical spectrum, (c) theoretical a carbon radical spectrum. The experimental spectrum (red trace) is overlaid on the theoretical spectra 


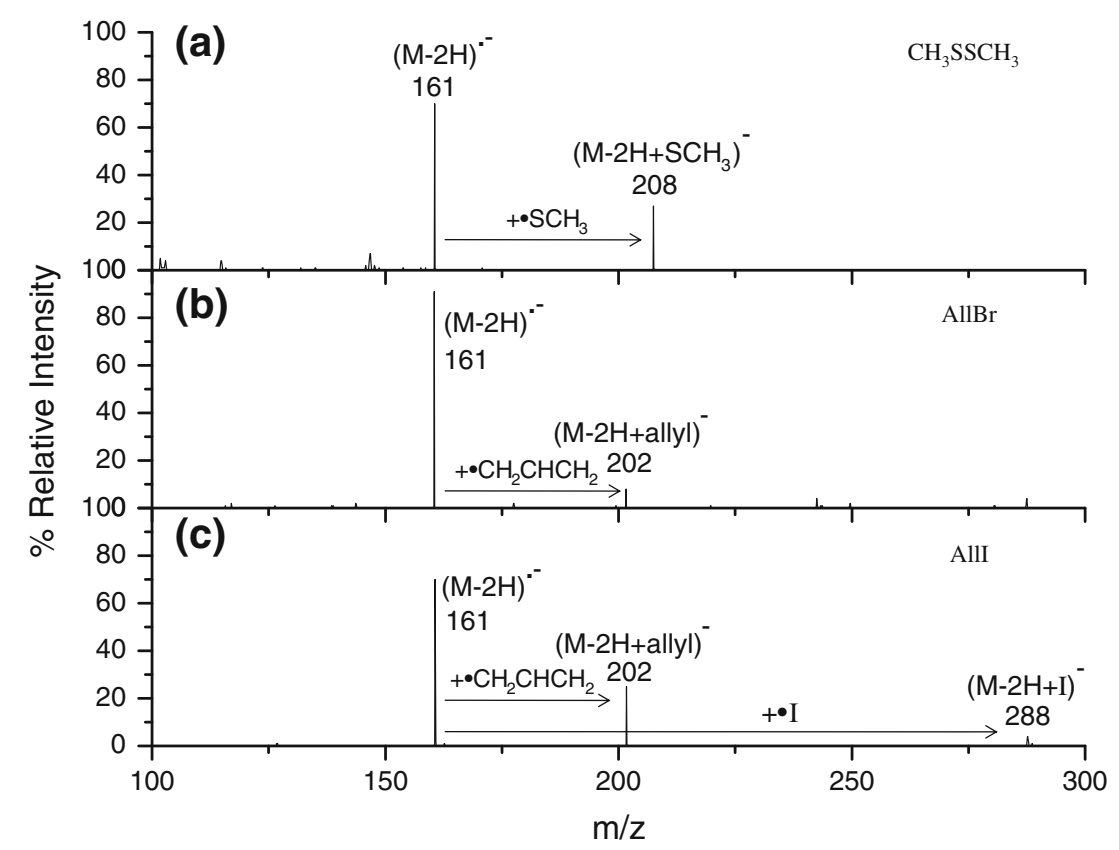

Figure 6. Ion-molecule reactions of the $\left[\mathrm{M}-2 \mathrm{H}^{0^{-}}\right.$radical anion of $N$-acetyl-cysteine with (a) dimethyl disulfide, (b) allyl bromide, and (c) allyl iodide. Pressure of the neutrals is ca. $10^{-7}$ Torr, reaction time is $400 \mathrm{~ms}$

\section{Conclusion}

It was shown that both hydrogen-deficient radical cations $\mathrm{M}^{\bullet+}$ and radical anions $(\mathrm{M}-2 \mathrm{H})^{\circ-}$ of cysteine derivatives can be generated in the gas phase via fragmentation of the $S$ nitrosylated precursors of these ions using electrospray ionization in either positive or negative ion mode. The way in which the radical is formed implies that the radical site is initially present on the sulfur atom.

The IRMPD and ion-molecule reactivity experiments strongly suggest that there is a substantial degree of radical migration from the sulfur to the $\alpha$-carbon position in the radical cation of $N$-acetyl cysteine formed via in-source fragmentation. This is the first evidence of radical rearrangement that has been shown using IRMPD spectroscopy and ion-molecule reactions. On the other hand, the radical cation formed via CID in the ion trap has much higher population of the sulfur-based radical.

Based on IRMPD spectroscopy and ion-molecule reactions, the radical anion of $N$-acetyl cysteine retains its initial structure of the sulfur-based radical. This is not an unexpected result since DFT calculations indicate that the radical at the $\alpha$-carbon position in the anion is much less stable, likely due to the absence of captodative stabilization as in the radical cation.

Studies are currently under way to detect radical rearrangement in small cysteine-containing peptides using the same approach presented here.

\section{Acknowledgments}

V.R. and S.O. acknowledge support from Northern Illinois University and a travel grant from the Center for Biochemical and Biophysical Studies of NIU. S.O. also acknowledges Michael Kullman for helping put together the computational set-up. R.A.J.O. thanks the ARC Centre of Excellence in Free Radical Chemistry and Biotechnology for financial support. J.O. and G.B. are supported by the Nederlandse Organisatie voor Wetenschappelijk Onderzoek (NWO). The authors gratefully acknowledge the skillful assistance of the FELIX staff.

\section{References}

1. Balagopalakrishna, C., Abugo, O., Horsky, J., Manoharan, P., Nagababu, E., Rifkind, J.: Superoxide produced in the heme pocket of the B-chain of hemogobin reacts with the B-93 cysteine to produce a thiyl radical. Biochemistry 37, 13194-13202 (1998)

2. Becker, A., Kabsch, W.: X-ray structure of pyruvate formate-lyase in complex with pyruvate and CoA: How the enzyme uses the Cys 418 thiyl radical for pyruvate cleavage. J. Biol. Chem. 277, 40036-40042 (2002)

3. Ehrenberg, A., Reichard, P.: Electron spin resonance of the ironcontaining protein B2 from ribonucleotide reductase. J. Biol. Chem. 247, 3485-3488 (1972)

4. Knauer, S., Buckel, W., Dobbek, H.: Structural basis for recutive radical formation and electron recycling in (R)-2-Hydroxyisocaproyl-CoA dehydratase. J. Am. Chem. Soc. (2011). doi:10.1021/ja1076537

5. Lepore, B., Ruzicka, F., Frey, P., Ringe, D.: The x-ray crystal structure of lysine-2,3-aminomutase from Clostridium subterminale. Proc. Natl. Acad. Sci. USA 102, 13819-13824 (2005)

6. Logan, D., Andersson, J., Sjoberg, B.-M., Nordlund, P.: A glycyl radical site in the crystal structure of a class III ribonucleotide reductase. Science 283, 1499-1504 (1999)

7. Mozziconacci, O., Sharov, V., Williams, T., Kerwin, B., Schoneich, C.: Peptide cysteine thiyl radicals abstract hydrogen atoms from surrounding amino acids: The photolysis of a cystine containing model peptide. J. Phys. Chem. B 112, 9250-9257 (2008)

8. Nauser, T., Casi, G., Koppenol, W., Schoneich, C.: Reversible intramolecular hydrogen transfer between cysteine thiyl radicals and glycine and alanine in model peptides: Absolute rate constants derived 
from pulse radiolysis and laser flash photolysis. J. Phys. Chem. B 112, 15034-15044 (2008)

9. Reitzer, R., Gruber, K., Jogl, G., Wagner, U., Bothe, H., Buckel, W., Kratky, C.: Glutamate mutase from Clostridium cochlearium: The structure of a coenzyme $\mathrm{B}_{12}$-dependent enzyme provides new mechanistic insights. Structure 7, 891-902 (1999)

10. Sivaraja, M., Goodin, D., Smith, M., Hoffman, B.: Identification by ENDOR of Trp191 as the free-radical site in cytochrome $c$ peroxidase compound ES. Science 245, 738-740 (1989)

11. Hioe, J., Savasci, G., Brand, H., Zipse, H.: The stability of $\mathrm{C} \alpha$ peptide radicals: Why glycyl radical enzymes? Chem. Eur. J. 17, 3781-3789 (2011)

12. Licht, S., Gerfen, G., Stubbe, J.: Thiyl radicals in ribonucleotide reductases. Science 271, 477-481 (1996)

13. Davies, M., Dean, R.: Radical- mediated protein oxidation. Oxford University Press, New York (1997)

14. Davies, M.: Protein and peptide alkoxyl radicals can give rise to Cterminal decarboxylation and backbone cleavage. Arch. Biochem. Biophys. 336, 163-172 (1996)

15. Davies, M.: Myeloperoxidase-derived oxidation: Mechanisms of bological damage and its prevention. J. Clin. Biochem. Nutr. 48, 8-19 (2011)

16. Headlam, H., Mortimer, A., Easton, C., Davies, M.: B-scission of C-3 ( $\beta$-carbon) alkoxyl radicals on peptides and proteins: A novel pathway which results in the formation of a $\alpha$-carbon radicals and the loss of amino acid side chains. Chem. Res. Toxicol. 13, 1087-1095 (2000)

17. Rauk, A., Armstrong, D.: Influence of B-sheet on the susceptibility of proteins to backbone oxidative damage: Preference for $\alpha \mathrm{C}$-centered radical formation at glycine residues of antiparallel $\beta$-sheets. $J . A m$. Chem. Soc. 122, 4185-4192 (2000)

18. Rauk, A., Yu, D., Armstrong, D.: Oxidative damage to and by cysteine proteins: An $\mathrm{Ab}$ initio study of the radical structures, $\mathrm{C}-\mathrm{H}, \mathrm{S}-\mathrm{H}$, and $\mathrm{C}-$ $\mathrm{C}$ bond dissociation energies, and transition structures for $\mathrm{H}$ abstraction by thiyl radicals. J. Am. Chem. Soc. 120, 8848-8855 (1998)

19. Schoneich, C.: Mechanisms of protein damage induced by cysteine thiyl radical formation. Chem. Res. Toxicol. 21, 1175-1179 (2008)

20. Hopkinson, A.: Radical cations of amino acids and peptides: Structures and stabilities. Mass Spectrom. Rev. 28, 655-671 (2009)

21. Sibrian-Vazquez, M., Escobedo, J., Lim, S., Samoei, G., Strongin, R.: Homocystamides promote free-radical and oxidative damage to proteins. Proc. Natl. Acad. Sci. USA 107, 551-554 (2010)

22. Andersson, C.O.: Mass spectrometric studies on amino acid and peptide derivatives. Acta Chem. Scand. 12, 1353 (1958)

23. Chu, I., Rodriquez, C., Lau, T.-C., Hopkinson, A.C., Siu, K.W.M.: Molecular radical cations of oligopeptides. J. Phys. Chem. B 104, 3393 $3397(2000)$

24. Masterson, D., Yin, H., Chacon, A., Hachey, D., Norris, J., Porter, N.: Lysine peroxycarbamates: Free radical-promoted peptide cleavage. $J$. Am. Chem. Soc. 126, 720-721 (2004)

25. Yin, H., Chacon, A., Porter, N., Masterson, D.: Free radical-induced site-specific peptide cleavage in the gas phase: Low-energy collisioninduced dissociation in ESI- and MALDI mass spectrometry. $J$. Am. Soc. Mass Spectrom. 18, 807-816 (2007)

26. Chacon, A., Masterson, D., Yin, H., Liebler, D., Porter, N.: N-terminal amino acid side-chain cleavage of chemically modified peptides in the gas phase: A mass spectrometry technique for $\mathrm{N}$-terminus identification. Bioorg. Med. Chem. 14, 6213-6222 (2006)

27. Wee, S., Mortimer, A., Moran, D., Wright, A., Barlow, C.K., O'Hair, R.A.J. Radom, L., Easton, C.J.: Gas-phase regiocontrolled generation of charged amino acid and peptide radicals. Chem. Commun. 4233-4235 (2006)

28. Barlow, C.K., Wright, A., Easton, C.J., O'Hair, R.A.J.: Gas-phase ionmolecule reactions using regioselectively generated radical cations to model oxidative damage and probe radical sites in peptides. Org. Biomol. Chem. 9, 3733-3745 (2011)

29. Liu, Z., Julian, R.: Deciphering the peptide iodination code: Influence on subsequent gas-phase radical generation with photodissociation ESI-MS. J. Am. Soc. Mass Spectrom. 20, 965-971 (2009)

30. Ly, T., Julian, R.: Residue-specific radical-directed dissociation of whole proteins in the gas phase. J. Am. Chem. Soc. 130, 351-358 (2008)

31. Diedrich, J., Julian, R.: Site-specific radical directed dissociation of peptides at phosphrylated residues. J. Am. Chem. Soc. 130, 12212-12213 (2008)

32. Ryzhov, V., Lam, A.K.Y., O'Hair, R.A.J.: Gas-phase fragmentation of long-lived cysteine radical cations formed via NO loss from protonated S-nitrosocysteine. J. Am. Soc. Mass Spectrom. 20, 985-995 (2009)

33. Steill, J., Zhao, J., Siu, C.-K., Ke, Y., Verkerk, U., Oomens, J., Dunbar, R., Hopkinson, A.C., Siu, K.W.M.: Structure of the observable histidine radical cation in the gas-phase: A captodative $\alpha$-radical ion. Angew. Chem. 120, 154-156 (2008)

34. Sinha, R., Maitre, P., Piccirillo, S., Chiavarino, B., Crestoni, M., Fornarini, S.: Cysteine radical cation: A distonic structure probed by gas phase IR spectroscopy. Phys. Chem. Chem. Phys. 12, 9794-9800 (2010)

35. Osburn, S., Steill, J., Oomens, J., O'Hair, R.A.J., Van Stipdonk, M., Ryzhov, V.: Structure and reactivity of the cysteine methyl ester radical cation. Chem. Eur. J. 17, 873-879 (2010)

36. Zhao, J., Siu, K.W.M., Hopkinson, A.C.: The cysteine radical cation: Structures and fragmentation pathways. Phys. Chem. Chem. Phys. 10, 281-288 (2008)

37. Lam, A.K.Y., Ryzhov, V., O'Hair, R.A.J.: Mobile protons vs. mobile radicals: Gas-phase unimolecular chemistry of radical cations of cysteine-containing peptides. J. Am. Soc. Mass Spectrom. 21, 1296$1312(2010)$

38. Moore, B., Blanksby, S., Julian, R.: Ion-molecule reactions reveal facile radical migration in peptides. Chem. Commun. 10, 5015-5017 (2009)

39. Fu, M., Li, S., Archibold, E., Yurkovich, M., Nash, J., Kenttamaa, H.: Reactions of an aromatic $\sigma, \sigma$-biradical with amino acids and dipeptides in the gas phase. J. Am. Soc. Mass Spectrom. 21, 1737-1752 (2010)

40. Li, S., Fu, M., Habicht, S., Pates, G., Nash, J.J., Kenttamaa, H.: Phenyl Radical Induced Damage to Dipeptides. J. Org. Chem. 74, 7724-7732 (2009)

41. Kirk, B., Harman, D., Blanksby, S.: Direct observation of the gas phase reaction of the cyclohexyl radical with dioxygen using a distonic radical ion approach. J. Phys. Chem. A 114, 1446-1456 (2010)

42. Lam, C.N.W., Chu, I.K.: Formation of anionic peptide radicals in vacuo. J. Am. Soc. Mass Spectrom. 17, 1249-1257 (2006)

43. Laskin, J., Yang, Z., Lam, C., Chu, I.K.: Charge-remote fragmentation of odd-electron peptide ions. Anal. Chem. 79, 6607-6614 (2007)

44. Coon, J.J., Shabanowitz, J., Hunt, D.F., Syka, J.E.P.: Electron transfer dissociation of peptide anions. J. Am. Soc. Mass Spectrom. 16, 880-882 (2005)

45. Pompella, A., Visvikis, A., Paolicchi, A., De Tata, V., Casini, A.: The changing faces of glutathione, a cellular protagonist. Biochem. Pharmacol. 66, 1499-1503 (2003)

46. Pyatkivskyy, Y., Ryzhov, V.: Coupling of ion-molecule reactions to liquid chromatography on a quadrupole ion trap mass spectrometer. Rapid Commun. Mass Spectrom. 22, 1288-1294 (2008)

47. Oepts, D., Van Der Meer, A., Van Amersfoort, P.: The free electron laser user facility FELIX. Infrared Phys. Technol. 36, 297-308 (1995)

48. Valle, J., Eyler, J., Oomens, J., Moore, D., Van Der Meer, A., Von Helden, G., Meijer, G., Hendrickson, C., Marshall, A., Blakney, G.: Free electron laser-fourier transform ion cyclotron resonance mass spectrometry facility for obtaining infrared multiphoton dissociation spectra of gaseous ions. Rev. Sci. Instrum. 76, 023103 (2005)

49. Polfer, N., Oomens, J., Moore, D., Von Helden, G., Meijer, G., Dunbar, R.: Infrared spectroscopy of phenylalanine $\mathrm{Ag}(\mathrm{I})$ and $\mathrm{Zn}(\mathrm{II})$ complexes in the gas phase. J. Am. Chem. Soc. 128, 517-525 (2006)

50. Marshall, A., Hendrickson, C., Jackson, G.: Fourier transform ion cyclotron resonance mass spectrometry: A primer. Mass Spectrom. Rev. 17, 1-35 (1998)

51. Polfer, N., Oomens, J.: Reaction products in mass spectrometry elucidated with infrared spectroscopy. Phys. Chem. Chem. Phys. 9, 3804-3817 (2007)

52. Frisch, M.J., Trucks, G.W., Schlegel, H.B., Scuseria, G.E., Robb, M.A. Cheeseman, J.R., Montgomery Jr., J.A., Vreven, T., Kudin, K.N., Burant, J.C., Millam, J.M., Iyengar, S.S., Tomasi, J., Barone, V., Mennucci, B., Cossi, M., Scalmani, G., Rega, N., Petersson, G.A., Nakatsuji, H., Hada, M., Ehara, M., Toyota, K., Fukuda, R., Hasegawa, J., Ishida, M., Nakajima, T., Honda, Y., Kitao, O., Nakai, H., Klene, M., Li, X., Knox, J.E., Hratchian, H.P., Cross, J.B., Bakken, V., Adamo, C., Jaramillo, J., Gomperts, R., Stratmann, R.E., Yazyev, O., Austin, A.J., Cammi, R., Pomelli, C., Ochterski, J.W., Ayala, P.Y., Morokuma, K., Voth, G.A., Salvador, P., Dannenberg, J.J., Zakrzewski, V.G., Dapprich, S., Daniels, A.D., Strain, M.C., Farkas, O., Malick, D.K., Rabuck, A.D., Raghavachari, K., Foresman, J.B., Ortiz, J.V., Cui, Q., Baboul, A.G., Clifford, S., Cioslowski, J., Stefanov, B.B., Liu, G., Liashenko, A., Piskorz, P., Komaromi, I., Martin, R.L., Fox, D.J., Keith, T., Al-Laham, M.A., Peng, C.Y., Nanayakkara, A., Challacombe, M., Gill, P.M.W., Johnson, B., Chen, W., Wong, M.W., Gonzalez, C., Pople, J.A.: GAUSSIAN 03 (Revision D.01). Gaussian Inc., Wallingford (2004)

53. Polfer, N., Oomens, J., Dunbar, R.: IRMPD spectroscopy of metal-ion/ tryptophan complexes. Phys. Chem. Chem. Phys. 8, 2744-2751 (2006) 
54. Polfer, N., Oomens, J., Dunbar, R.: Alkali metal complexes of the dipeptides PheAla and AlaPhe: IRMPD spectroscopy. Chem. Phys. Chem. 9, 579-589 (2008)

55. Chu, I., Zhao, J., Xu, M., Siu, S., Hopkinson, A.C., Siu, K.W.M.: Are the radical centers in peptide radical cations mobile? The generation, tautomerism, and dissociation of isomeric $\alpha$-carbon-centered triglycine radical cations in the gas phase. J. Am. Chem. Soc. 130, 7862-7872 (2008)

56. Siu, C.-K., Zhao, J., Laskin, J., Chu, I., Hopkinson, A.C., Siu, K.W.M.: Kinetics for tautomerization and dissociations of triglycine radical cations. J. Am. Soc. Mass Spectrom. 20, 996-1005 (2009)

57. Bohme, D.K.: Proton transport in the catalyzed gas-phase isomerization of protonated molecules. Int. J. Mass Spectrom. Ion Processes 115, 95 110 (1992)
58. Mourgues, P., Chamot-Rooke, J., Nedev, H., Audier, H.-E.: Spontaneous and catalyzed isomerizations of the acetamide radical cation. J. Mass Spectrom. 36, 102-104 (2001)

59. Gauld, J.W., Audier, H.E., Fossey, J., Radom, L.: Water-catalysed interconversion of conventional and distonic radical cations: Methanol and methyleneoxonium radical cations. J. Am. Chem. Soc. 118, 6299$6300(1996)$

60. Viehe, H.G., Janousek, Z., Merenyi, R., Stella, L.: The captodative effect. Acc. Chem. Res. 18, 148-154 (1985)

61. Sustmann, R., Korth, H.-G.: The captodative effect. Adv. Phys. Org. Chem. 26, 131-178 (1991)

62. Easton, C.J.: Free-radical reactions in the synthesis of $\alpha$-amino acids and derivatives. Chem. Rev. 97, 53-82 (1997) 